\title{
Diode Laser Surgery of Recurrent White Lesion of the Lip: Clinicopathological Consideration and Cosmetic Outcome
}

\author{
Domenico De Falco ${ }^{1}$, Daniela Di Venere ${ }^{1}$, Eugenio Maiorano ${ }^{2}$ \\ 1. Dentistry, University of Bari Aldo Moro, Bari, ITA 2. Department of Emergency and Organ Transplantation, \\ University of Bari Aldo Moro, Bari, ITA
}

Corresponding author: Domenico De Falco, defalcodomenico@ymail.com

\begin{abstract}
Conventional surgery for potentially malignant lesions of the lip may result in unaesthetic sequela. Diode laser allows a careful surgical excision of lip lesions without intraoperative bleeding and stitches, promoting a fast mucosal healing, thereby leading to a complete restitutio ad integrum of lip mucosa without aesthetic complications.
\end{abstract}

Categories: Dentistry

Keywords: diode laser, leukoplakia, oral surgery

\section{Introduction}

With a worldwide prevalence of $4.4 \%$, oral potentially malignant disorders (OPMDs) are relatively common tissue changes that may precede squamous cell carcinoma, the most common malignancy of the oral mucosa accounting for the $80 \%$ to $90 \%$ of all oral cancers [1,2]. The most common OPMDs are leukoplakia, speckled leukoplakia, erythroplakia, and actinic cheilitis [3,4]. Leukoplakia is defined by the World Health Organization as "a white patch or plaque that cannot be characterized clinically or pathologically as any other disease" [2]. Leukoplakias occurring on the lower lip as well as on the floor of the mouth and lateral tongue may show more epithelial dysplasia or malignant transformation [3,5]. Overall, persistent and/or recurrent white lesions of the oral mucosa create a suspicion of malignancy and usually require incisional biopsy or complete excision $[2,4,5]$.

We report a case of recurrent white lesion of the lower lip treated with laser diode excision for an optimal aesthetic outcome.

\section{Case Presentation}

Received 03/26/2020 Review began 04/02/2020 Review ended 04/06/2020 Published 04/08/2020

๑ Copyright 2020 De Falco et al. This is an open access article distributed under the terms of the Creative Commons Attribution License CC-BY 4.0, which permits unrestricted use, distribution, and reproduction in any medium, provided the original author and source are credited.
A 32-year-old woman was referred for management of a recurrent lesion of the lower lip. Clinical examination revealed a white plaque (Figure $1 a$ ). The lesion was described by the patient as chronic, and it had recurred despite having undergone treatment twice previously. No other white lesions were detectable in the oral cavity. Diode laser excision of the entire lesion followed by histological examination was suggested, and the patient agreed. Under light conscious sedation to reduce dental anxiety and with local infiltration of anesthesia, the lesion was removed with wide lateral and deep margins using a diode laser with a wavelength of $980 \pm 10 \mathrm{~nm}$ in continuous wave, an output energy of $1 \mathrm{~W}$, and a fiber of 320 microns (Figures $1 b, 1 c$ ). Bleeding was absent during the entire procedure, and no stitches were necessary. The tissue was sent for a histological examination leading to the diagnosis of friction keratosis. No morphological alterations related to the thermal cut of the diode laser were observed (Figure 1d). The lip mucosa showed complete healing after 14 days without cosmetic complications (Figure 1e). 


\section{Cureus}
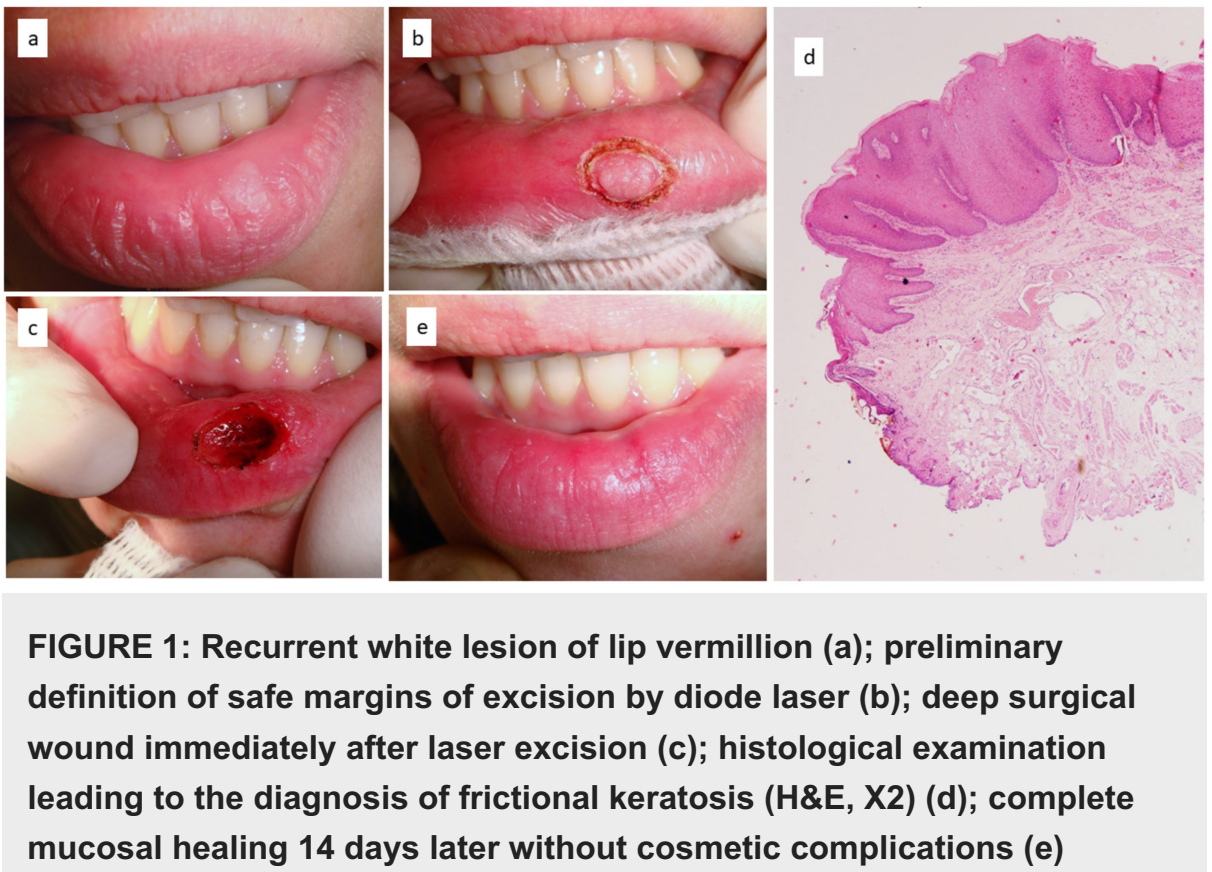

\section{Discussion}

Although rare, several lesions such as actinic keratosis, leukoplakia, carcinoma in situ, and superficially invasive carcinomas may occur in the lower lip $[2,3,5]$. Current treatment modalities include cryosurgery or electrosurgery, topical chemotherapy, or lip shave, but all have limitations including minor deformation of the lip [6].

The diode laser, potassium titanyl phosphate (KTP), carbon dioxide (CO2), neodimio:YAG (yttrium aluminum garnet), and erbium:YAG are medical devices widely used in oral surgery $[7,8]$. Nevertheless, among all lasers with surgical capabilities, especially contextual cut and coagulation, the diode laser is surely the most commonly used for excision of benign and malignant proliferating lesions of the oral cavity, photocoagulation of both small and large vascular malformations of the head and neck, and adjunctive periodontal therapy [9-12].

The advantages of diode laser are the absence of intraoperative bleeding, reduction of postoperative edema, unnecessary stitches, and fast mucosal healing by second intention, avoiding unaesthetic complications for lesions occurring in the lip vermilio $[13,14]$.

As in the reported case, white lesions of the lip surely need decisive surgical intervention, especially when persistent and/or recurrent and when an incisional biopsy cannot be performed [3,5]. Excision should have safe lateral margins and adequate depth, while avoiding cosmetic complications as much as possible. The diode laser used in the current case allows for careful and decisive excision of the lesion without thermal damage to the surrounding tissues, with an absence of bleeding and unnecessary stitches, resulting in faster healing of the surgical wound and a pleasing cosmetic outcome [13,14].

Diode laser surgery can simplify oral surgery procedures, especially in children. It is also useful in patients with contagious infectious diseases (such as hepatitis C or B viruses and HIV) as it minimizes the risk of bleeding and potential-related infectious concerns during perioperative care $[15,16]$. In the case of dental anxiety, conscious sedation is suggested as it can improve the acceptability of the treatment $[17,18]$.

\section{Conclusions}

The diode laser represents a safe and decisive tool for surgical and nonsurgical treatments in the oral cavity. For white lesions occurring in the lip, diode laser surgery allows for meticulous treatment and helps prevent cosmetic complications while providing effective and safe recovery.

\section{Additional Information}

\section{Disclosures}

Human subjects: Consent was obtained by all participants in this study. Conflicts of interest: In compliance with the ICMJE uniform disclosure form, all authors declare the following: Payment/services info: All authors have declared that no financial support was received from any organization for the 
submitted work. Financial relationships: All authors have declared that they have no financial relationships at present or within the previous three years with any organizations that might have an interest in the submitted work. Other relationships: All authors have declared that there are no other relationships or activities that could appear to have influenced the submitted work.

\section{References}

1. Johnson NW, Jayasekara P, Amarasinghe AA: Squamous cell carcinoma and precursor lesions of the oral cavity: epidemiology and aetiology. Periodontology 2000. 2011, 57:19-37. 10.1111/j.1600-0757.2011.00401.x

2. Reibel J, Gale N, Hille J, et al.: Oral potentially malignant disorders and oral epithelial dysplasia . WHO Classification of Head and Neck Tumours. 4th ed. El-Naggar AK, Chan JKC, Grandis JR, Takata T, Slootweg PJ (ed): International Agency for Research on Cancer, Lyon; 2017. 112-115.

3. Warnakulasuriya S, Ariyawardana A: Malignant transformation of oral leukoplakia: a systematic review of observational studies. J Oral Pathol Med. 2016, 45:155-166. 10.1111/jop.12339

4. Kumar S, Debnath N, Ismail MB, et al.: Prevalence and risk factors for oral potentially malignant disorders in Indian population. Adv Prev Med. 2015, 2015:208519. 10.1155/2015/208519

5. Sarmento DJS, Miguel MCC, Queiroz LM, et al.: Actinic cheilitis: clinicopathologic profile and association with degree of dysplasia. Int J Dermatol. 2014, 53:466-472. 10.1111/ijd.12332

6. Sayan A, Wijesinghe S, Paraneetharan S, Ilankovan V: Revisiting lip shave: a solution for disorders of the vermilion border. Br J Oral Maxillofac Surg. 2018, 56:60-63. 10.1016/j.bjoms.2017.11.014

7. Bargiela-Pérez P, González-Merchan J, Díaz-Sanchez R, et al.: Prospective study of the 532 nm laser (KTP) versus diode laser $980 \mathrm{~nm}$ in the resection of hyperplastic lesions of the oral cavity. Med Oral Patol Oral Cir Bucal. 2018, 23:78-85. 10.4317/medoral.21812

8. Suter VG, Altermatt HJ, Bornstein MM: A randomized controlled clinical and histopathological trial comparing excisional biopsies of oral fibrous hyperplasias using CO2 and Er:YAG laser. Lasers Med Sci. 2017, 32:573-581. 10.1007/s10103-017-2151-8

9. Limongelli L, Capodiferro S, Tempesta A, et al.: Early tongue carcinomas (clinical stage I and II): echoguided three-dimensional diode laser mini-invasive surgery with evaluation of histological prognostic parameters. A study of 85 cases with prolonged follow-up. Lasers Med Sci. 2019, 35:751-758. 10.1007/s10103-019-02932-Z

10. Limongelli L, Tempesta A, De Caro A, et al.: Diode laser photocoagulation of intraoral and perioral venous malformations after tridimensional staging by high definition ultrasonography. Photobiomodul Photomed Laser Surg. 2019, 37:722-728. 10.1089/photob.2019.4635

11. Capodiferro S, Limongelli L, Tempesta A, Maiorano E, Favia G: Diode laser treatment of venous lake of the lip. Clin Case Rep. 2018, 22:1923-1924. 10.1002/ccr3.1735

12. Capodiferro S, Tempesta A, Limongelli L, Maiorano E, Benedicenti S, Favia G: Nonsurgical periodontal treatment by erbium:YAG laser promotes regression of gingival overgrowth in patient taking cyclosporine A: a case report. Photobiomodul Photomed Laser Surg. 2019, 37:53-56. 10.1089/photob.2018.4478

13. Ortega-Concepción D, Cano-Durán JA, Peña-Cardelles JF, Paredes-Rodríguez VM, González-Serrano J, López-Quiles J: The application of diode laser in the treatment of oral soft tissues lesions. A literature review. J Clin Exp Dent. 2017, 9:e925-e928. 10.4317/jced.53795

14. Angiero F, Parma L, Crippa R, Benedicenti S: Diode laser $(808 \mathrm{~nm})$ applied to oral soft tissue lesions: a retrospective study to assess histopathological diagnosis and evaluate physical damage. Lasers Med Sci. 2012, 27:383-388. 10.1007/s10103-011-0900-7

15. Giuliani M, Tumbarello M, Marino M, et al.: Dental hygienists behaviour towards HIV-positive patients in highly active antiretroviral therapy era: a pilot survey. Int J Dent Hyg. 2011, 9:204-210. 10.1111/j.16015037.2010.00472.x

16. Rungsiyanont S, Vacharotayangul P, Lam-Ubol A, Ananworanich J, Phanuphak P, Phanuphak N: Perceived dental needs and attitudes toward dental treatments in HIV-infected Thais. AIDS Care. 2012, 24:1584-1590. 10.1080/09540121.2012.663884

17. Rephaeli R, Rehktman D, Gross I, Weiser G: Sedation provided for consultations in the pediatric emergency department: another perspective. Isr Med Assoc J. 2020, 22:5-7.

18. Dell'Olio F, Capodiferro S, Lorusso P, et al.: Light conscious sedation in patients with previous acute myocardial infarction needing exodontia: an observational study. Cureus. 2019, 30:6508. 10.7759 /cureus. 6508 